\title{
25th Growth Percentile
}

National Cancer Institute

\section{Source}

National Cancer Institute. 25th Growth Percentile. NCI Thesaurus. Code C98263.

An indication that an individual ranks the same or more than 25 percent of the reference population for a given attribute. 